\title{
Hypertension, Brain Damage and Cognitive Decline
}

\author{
Dariusz Gąsecki • Mariusz Kwarciany • Walenty Nyka • \\ Krzysztof Narkiewicz
}

Published online: 23 October 2013

(C) The Author(s) 2013. This article is published with open access at Springerlink.com

\begin{abstract}
Loss of cognitive function is one the most devastating manifestations of ageing and vascular disease. Cognitive decline is rapidly becoming an important cause of disability worldwide and contributes significantly to increased mortality. There is growing evidence that hypertension is the most important modifiable vascular risk factor for development and progression of both cognitive decline and dementia. High blood pressure contributes to cerebral small and large vessel disease resulting in brain damage and dementia. A decline in cerebrovascular reserve capacity and emerging degenerative vascular wall changes underlie complete and incomplete brain infarcts, haemorrhages and white matter hyperintensities. This review discusses the complexity of factors linking hypertension to brain functional and structural changes, and to cognitive decline and dementia. The evidence for possible clinical markers useful for prevention of decreased cognitive ability, as well as recent data on vascular mechanism in the pathogenesis of cognitive decline, and the role of antihypertensive therapies in long-term prevention of late-life cognitive decline will be reviewed.
\end{abstract}

Keywords Ageing $\cdot$ Atherosclerosis $\cdot$ Brain .

Cerebrovascular disease $\cdot$ Cognition $\cdot$ Cognitive decline .

Dementia $\cdot$ Hypertension $\cdot$ Risk factors $\cdot$ Treatment

D. Gąsecki $\cdot$ M. Kwarciany $\cdot$ W. Nyka

Department of Neurology of Adults, Medical University of Gdańsk, Gdańsk, Poland

K. Narkiewicz

Hypertension Unit, Department of Hypertension and Diabetology,

Medical University of Gdańsk, Gdańsk, Poland

K. Narkiewicz $(\square)$

Department of Hypertension and Diabetology,

Medical University of Gdańsk, Debinki 7c, 80-952 Gdańsk, Poland

e-mail:knark@gumed.edu.pl

\section{Introduction}

Arterial hypertension contributes to both the development and progression of cerebrovascular disease [1]. There is growing evidence that hypertension is the most powerful modifiable risk factor for cerebral vessel dysfunction and might contribute to consequent cognitive decline [2,3•]. The relationship among ageing, hypertension and cognitive function is complex and not completely understood. Nevertheless, blood pressure might be considered a marker of cerebrovascular health [4].

This review examines first, the epidemiology of dementia; second, the evidence linking hypertension, ageing and cognitive dysfunction; third, potential mechanisms underlying this link; fourth, the benefits of antihypertensive treatment in prevention of cognitive decline.

\section{Epidemiology of Dementia}

Increasing life expectancy observed worldwide results in a growing prevalence of cognitive decline and dementia. In the year 2000 , the worldwide number of subjects with dementia was estimated at about 25 million, corresponding to $6.1 \%$ of the population 65 years of age and older and to $0.5 \%$ of the worldwide population [5]. Almost $60 \%$ of all demented subjects were female. The worldwide annual cost of dementia increased between 2005 and 2009 by $34 \%$ from 315 billion to 421 billion USD [6]. It is forecasted that the number of demented elderly will increase to 63 million in 2030 and to 114 million in 2050 [5]. Because of the magnitude of the problem dementia is clearly a burning medical, social and economic burden.

Cognitive decline is a part of a natural history of brain ageing. Cognitive decline may take different forms depending on the severity of the process - from physiological cognitive 
ageing through mild cognitive impairment (MCI), a cognitive decline greater than expected for an individual's age and education, however not affecting patients activities of daily living, till dementia, a state in which cognitive impairment is affecting activities of daily living. Many patients with MCI have minor histopathological Alzheimer's disease (AD) changes, and more than half progress to full blown AD [7]. MCI patients can be divided into amnestic and non-amnestic subtypes [8]. Amnestic MCI (30\% of MCI patients) likely represents a prodromal form of $\mathrm{AD}$, with about $12 \%$ converting to $\mathrm{AD}$ each year [9].

Impairment of memory, abstract thinking and judgment are the hallmarks of dementia. Clinical assessment besides memory includes evaluation of language, attention, visuospatial abilities and executive functions.

Dementia syndromes are divided into neurodegenerative disease, vascular dementia $(\mathrm{VaD})$ and mixed variants. $\mathrm{AD}$, being the most common neurodegenerative form, accounts for approximately $65 \%$ of all cases of dementia in the white population [10]. Vascular dementia constitutes the second most common type of dementia, accounting for 15 to $20 \%$ of all cases of dementia [11]. Of note, "vascular dementia" is a concept rather than a nosological entity. It encompasses a variety of conditions and dementia mechanisms including ischaemic, ischaemic-hypoxic or haemorrhagic brain lesions as a result of cerebrovascular disease and cardiovascular pathological changes [12].

Although the majority of dementias are primary neurodegenerative diseases of unknown cause, recent studies have shown that cerebrovascular disease and microscopic vascular lesions are frequently found in patients affected by those conditions [13••, 14]. Moreover, cerebrovascular disease has been shown to be associated with more severe cognitive decline in $\mathrm{AD}$, the most common cause of dementia $[15,16]$.

\section{Blood Pressure and the Risk of Cognitive Decline}

The relationship between blood pressure (BP) and cognition has been examined across various neuropsychological domains. This relationship is strongly influenced by age. Furthermore, the moment of blood pressure assessment is of critical importance, and one should discriminate crosssectional observations from long-term follow-up studies taking into account the role of BP levels in the years preceding cognitive decline.

\section{Cross-Sectional Studies}

In younger patients, increased BP has been associated with impaired cognition. A recent study by Shehab et al. assessed the relationship between cognitive performance and white coat hypertension and borderline hypertension in a cohort of relatively young individuals (mean age $\pm \mathrm{SD}, 38.2 \pm$ 10.8 years). An analysis of clinic and 24-h ambulatory blood pressure monitoring and cognitive performance parameters showed lower cognitive function in patients with white coat hypertension (memory) and borderline hypertension (slower reaction time) compared with controls [17].

Mahoney et al. have recently shown that in individuals aged $>70$, those with low systolic blood pressure (SBP) demonstrate worse executive attention than individuals with normal to high SBP. Diastolic blood pressure (DBP) had no significant effect in this study. The authors suggested that the maintenance of optimal SBP levels in older adults might be crucial for optimal cognitive functions that depend on the frontal lobes [18].

In the group of very old individuals (Australian centenarians, mean age 101 years), low SBP and narrower pulse pressure were associated with poorer cognitive (measured by MMSE score) and functional status (measured using the Katz Index of Independence in Activities of Daily Living) [19]. The same findings were found in a cohort of Polish patients [20].

Taken together, these findings indicate that normal blood pressure is associated with the optimal cognitive performance independent of age. In the elderly, a reversed cross-sectional relationship between blood pressure and cognition might be secondary to brain atrophy, neuronal death and disturbances in cholinergic neurotransmission (see below) or reflect reversed epidemiology resulting from high hypertension-related stroke mortality in younger patients. Poor cognitive performance in elderly with currently low BP is especially pronounced in those with a history of hypertension. Thus, the relationship between BP and dementia might be somehow similar to that between hypertension and congestive heart failure. Hypertension might contribute to the development of both cognitive decline and heart failure at earlier stages of the diseases. A drop in blood pressure reflects failure of compensatory mechanisms, indicates a severe stage of the disease and is probably associated with irreversibility of the process.

\section{Long-Term Studies}

Baseline high blood pressure in middle-aged subjects has been linked to future cognitive decline, mild cognitive impairment and dementia [21-24]. This association was especially evident in studies focussing on $\operatorname{VaD}[25,26]$. Among different BP components, SBP appears to be the strongest predictor of cognitive decline in most of the studies.

The role of midlife BP in the development of cognitive decline has been recently re-assessed in several important publications. Elevated BP was associated with faster cognitive decline in patients diagnosed with MCI. Over a 2-year observation of 1,385 subjects diagnosed with $\mathrm{MCI}$, elevated $\mathrm{BP}$ (mainly SBP) was associated with impaired visuomotor sequencing, set shifting and naming [27]. 
In the Hoorn Study, Reijmer et al. investigated the relation between vascular risk factors and late-life cognitive performance after 15 years of follow-up in a cohort of 380 nondemented subjects (mean baseline age $58 \pm 6$ years). Individuals with poor information-processing speed had higher levels of systolic blood pressure at baseline [mean difference (SE) 11.6 (2.6) $\mathrm{mmHg}, p<0.001$ ], and the relationship gradually attenuated with increasing age [28].

In the Honolulu Heart Program/Honolulu Asia Aging Study, a 25-year observation of middle-aged subjects (mean age, 54 years) indicated that $27 \%$ of dementia cases could be attributed to untreated mid-life levels of SBP $>120 \mathrm{mmHg}$, which translates into 17 excess cases per 1,000. The novel finding of the study was that there were $17.7 \%$ of cases that were attributable to prehypertensive levels (SBP 120-< $140 \mathrm{mmHg}$ ) of BP [29•].

The relationship between mid-life BP and cognitive decline has also been recently confirmed by the 40 -year follow-up study of a population-based cohort of the Uppsala Longitudinal Study of Adult Men. Of 2,268 individuals initially enrolled in the study, 349 developed dementia. Systolic blood pressure increased the risk of vascular and all-type dementia [30॰]. The risk was further potentiated by other cardiovascular risk factors, which is consistent with the results of another study demonstrating the impact of obesity-related metabolic abnormalities on cognitive performance [31].

Importantly, hypertension usually coexists with lipid disorders (even in $>50 \%$ of individuals over 55 years of age) [32-34] Thus, the link between hypertension and cognitive function can be affected by coexisting dyslipidaemia and its treatment with statins, which might increase the risk of cognitive impairments, especially in elderly patients (http://www. fda.gov/drugs/drugsafety/ucm293101.htm). While the abovementioned evidence supporting the contribution of midlife hypertension to cognitive decline is growing, the impact of late-life BP is more controversial. The results of the earlier studies evaluating the influence of late-life BP on cognition were conflicting. Some of the investigators reported a significant effect of hypertension on cognitive decline [35, 36], while the others found no effect $[37,38]$ or suggested a Ushape relationship between BP and cognitive function [39, 40]. Several recent studies have revisited this issue.

Yasar et al. analysed the association of late-life ( $>70$ years) blood pressure on cognitive performance in a cohort of older, non-demented participants in the Women's Health and Aging Study II. Cognitive abilities were assessed at baseline and after 9-year follow-up. In a group aged 70-75 years, high PP $\geq 71 \mathrm{mmHg}$ was associated with impaired verbal learning while in the group aged 76-80 years, high $\mathrm{SBP} \geq 160 \mathrm{mmHg}$ or $\mathrm{PP} \geq 84 \mathrm{mmHg}$ was associated with decreased executive functions. These findings indicate that not only midlife but also late-life BP may be associated with cognitive decline [41].
In a group of Korean patients aged 40-95 years, hypertension increased the risk of $\mathrm{VaD}$ by more than two fold in both men and women. This association was attenuated in patients older than 65 , but remained significant in men. This study showed no interaction between hypertension and diabetes on the risk of dementia [42].

In the Hisayama study 668 non-demented Japanese patients aged 65-79 years were followed up for 17 years. Within that time 76 subjects developed vascular dementia. After adjusting for confounding factors, subjects with prehypertension and stage 1 or stage 2 hypertension had 3.0-, 4.5- and 5.6-fold greater risk of vascular dementia, respectively, compared with subjects with normal blood pressure [43].

The relationship between MCI and the risk of progression to dementia was assessed by Oveisgharan and Hachinski. Nine hundred ninety individuals with a mean age of 83 years, diagnosed with MCI (affecting memory, executive functions or both) were followed up for up to 5 years. The rate of progression to dementia was highest in patients with impaired executive functions $(57.7 \%$ having hypertension progressed to dementia compared with $28.0 \%$ having normotension, $p=0.02$ ) [44].

Interestingly, a BP decrease has been shown to precede a clinical manifestation of dementia in the elderly and very elderly subjects $[45,46]$. As an explanation, neuronal death and disturbances in cholinergic neurotransmission affecting the autonomic centres in the brain have been suggested. Furthermore, progressive physical inactivity associating cognitive decline may be also a substantial factor leading to a fall in blood pressure [47].

\section{Alzheimer's Disease}

While the strong association between elevated blood pressure and future development of $\mathrm{VaD}$ is well documented, the relationship between hypertension and $\mathrm{AD}$ is less clear [25, 26, 45, 48-54].

The recently published Uppsala Longitudinal Study of Adult Men, despite extended follow-up (up to 40 years), was not able to find any relationship between middle-life BP and the risk of AD [30 ]. Similarly, other studies found no association between elevated $\mathrm{BP}$ and $\mathrm{AD}[44,55]$. In fact, increased DBP was significantly associated with the decreased development of $\mathrm{AD}$ [55].

\section{Mechanism Underlying the Link Between Hypertension and Cognitive Decline}

Cerebrovascular dysfunction plays the key role in cognitive and behavioural impairment. With ageing profound alterations in the structure, function and organisation of cerebral 
blood vessels occur. First, the number of cerebral capillaries in the cortex is reduced, and their basement membranes become thickened and fibrotic [56]. White matter vessels appear more tortuous with ageing [57]. These alterations result in reduction of resting cerebral blood flow (CBF), attenuation of cerebrovascular reserves and dysfunction of the mechanisms regulating the cerebral circulation [56-58]. These age-related alterations might be potentiated by hypertension.

Hypertension-related cognitive decline is a consequence of interplay between functional blood flow reorganisation and brain vascular damage. Focal and regional dissociations in blood flow and function lead to lesions affecting both grey and white matter, manifesting as complete and incomplete microinfarcts, haemorrhages and white matter hyperintensities (WMHs).

\section{Failure of the Cerebral Regulatory Function}

Recent evidence has emerged showing that hypertension itself has a direct negative effect on cerebral vasoreactivity that is comparable to that observed in stroke [59•]. Consequently, hypertension might increase the risk of microvascular brain damage and impairment in mobility, cognition and mood [60].

Pressure autoregulation and $\mathrm{CO}_{2}$ reactivity are the two clinically relevant biomarkers of vascular reserve [61]. Impairment of the vascular reserve might mediate the link between BP and cognition. The neurovascular regulatory systems are widely involved in cognitive and motor functions. In case of failure of the cerebral regulatory function, including cholinergic neuronal processes, the brain might become more prone to hypertension-related damage and cognitive decline [62].

\section{Structural Brain Changes}

\section{Grey Matter Changes}

Both human ageing and hypertension are associated with brain atrophy [63•]. The structural changes that are noted in patients with MCI involve mesial and lateral temporal regions as well as cingulate, parietal and mid-frontal areas. The earliest changes however do occur within the hippocampus and entorhinal cortex [64]. Regions emerging as especially vulnerable to advanced age and to essential hypertension include the prefrontal cortex, hippocampus, inferior temporal cortex $[65,66]$ and inferior parietal lobule [67]. Of note, also brain regions that are only moderately vulnerable to ageing, e.g., the supplementary motor areas [68], cuneus [69], thalamus [70] and entorhinal cortex [67], are affected by hypertension. Thus, high blood pressure may affect the grey matter structure not only by potentiation of age-dependent changes, but also by mechanisms that are hypertension-specific and independent of ageing.

\section{White Matter Changes}

One of the most common manifestations of brain ageing is reduction in white matter integrity [71], which radiologically manifests as a leukoaraiosis - areas of decreased density on CT scans or increased signal intensity on T2/FLAIR sequences on MRI scans [72]. White matter hyperintensities are associated with future risk of stroke, cognitive decline, dementia and death [73•]. Although the aetiology of WMHs is not clear, they are believed to be one of the manifestations of cerebral small vessel disease [74, 75••].

The association between hypertension and WMHs is well established [76, 77]. High blood pressure is related to cerebral WMH progression [78 ${ }^{\circ}$ and to increased risk of incident infarcts [79]. Both baseline BP and its increase over a mean of 7 years have been associated with greater WMH volume [80]. A recent study evaluating WMH progression over a relatively short period of time has shown that high blood pressure or a history of hypertension was associated with greater deep WMH volume in the frontal lobe [81], indicating that the frontal lobe is especially susceptible to the hypertension-related white matter degradation. Hypertension may be associated not only with visible lesions, but also with white matter microstructure alterations, suggesting an important role of blood pressure in age-related cerebral tissue damage [82].

Larger WMH volume in hypertensive individuals has been linked to inflammatory factors, endothelial dysfunction and poorly perfused watershed areas [83]. An increase in WMH volume is lower in controlled treated hypertensives compared with uncontrolled untreated hypertensives, despite the higher baseline WML load [78•]. Thus, successful hypertension management might reduce progression of WML.

There is accumulating evidence that the negative effect of elevated blood pressure on lifelong cognitive ageing is probably mainly mediated by WMHs [84]. An increase of WMH volume is associated with a decrease in episodic memory and executive function. Interestingly, the evolution of existing WMHs was more relevant than the formation of new ones [85]. The presence of retinopathy, as another marker of small vessel disease, has recently been shown to correspond to cognitive impairment [86]. Additionally, cerebral microbleeds (CMBs), another type of brain lesion related to the pathology of small vessels, might also be associated with hypertension and cognitive decline. However, the role of CMBs as predictors of disease needs to be further elucidated [87].

\section{Large Artery Dysfunction}

Both cognitive decline and brain damage might be related to impairment of large artery function. Pulse pressure (PP), a marker of arterial stiffness, has been connected with the risk of cognitive decline $[88]$ and $\mathrm{AD}[89,90]$, impaired $\mathrm{A} \beta$ removal 
[91] and higher prevalence of WMHs [92]. Elevated pulse pressure increases the risk of cognitive decline and impairment in language abilities in non-demented older adults [93]. In another study in middle-aged healthy individuals, PP was an independent predictor of both episodic memory performance and speed of memory retrieval [94].

Nation et al. have recently assessed the relation between late-life PP and the severity of post-mortem histopathological indicators of cerebrovascular disease and cerebral amyloid angiopathy in autopsy-confirmed AD patients. Higher PP was associated with more severe cerebrovascular disease, but not with the presence of cerebral amyloid angiopathy or the severity of $\mathrm{AD}$, indicating late-life $\mathrm{PP}$ is associated with cerebrovascular disease rather than with $\mathrm{AD}$ itself [95].

Pulse pressure is an indirect marker of arterial stiffness, which might be much more precisely assessed by measurement of pulse wave velocity (PWV). The analysis of the association between PWV and cognitive function performed by Rabkin and Jarvie indicates the inverse relationship between PWV and cognitive performance. Moreover, $\mathrm{PWV}$ is higher in patients with $\mathrm{VaD}$ compared with controls and $\mathrm{AD}$ patients [96-]. Those findings are consistent with the results of a recent cross-sectional study by Zhong et al., which has shown elevated carotid-femoral PWV $(>12 \mathrm{~m} / \mathrm{s})$ to be associated with worse cognitive function in the elderly population (mean age 75 years) [97].

\section{Renin-Angiotensin System}

Recent research supports an important role of the reninangiotensin system in both brain ageing [98] and in dementia progression [99]. The effects of angiotensin II on vascular and metabolic homeostasis, amyloid metabolism, as well as on learning and memory might explain this link. Angiotensin is active in the nucleus tractus solitarius and the dorsolateral ventral medulla-BP regulatory area [100]. Blood angiotensin is also known to influence the neuroendocrine system and the brain through the circumventricular organ [101].

\section{Altered Metabolism}

Cerebral metabolism is specifically altered in patients with dementia, as indicated by FDG-PET studies [102]. Reduction in the cerebral metabolic rate of glucose, an index of neural metabolic activity and density [103], can precede the onset of dementia by many years [104]. Finally, PET-amyloid tracers can discriminate normal patients at higher versus lower risk for $\mathrm{AD}$, and the retention of amyloid tracer in a healthy person is a risk factor for later cognitive decline $[102,105]$.

\section{Genetic Factors}

Several recent studies have assessed the association between genetic risk factors of dementia (ApoE ع4), WMLs and hypertension $[29 \bullet, 106,107]$. Yasuno et al. have demonstrated the synergistic effect of hypertension and the ApoE $\varepsilon 4$ allele on the acceleration of cognitive decline in elderly patients [108]. Schuur et al. have shown that ApoE $\varepsilon 4$ homozygotes had more WML, lacunes and microbleeds than those without the $\varepsilon 4$ allele [109].

\section{Psychosocial Stress}

The term "hypertension" itself suggests a relationship with some kind of "tension", and high BP has been linked to greater psychosocial stress $[110,111]$. However, longitudinal studies have revealed that the overall relationship between psychological factors and hypertension is rather low [112•]. Nevertheless, normotensive subjects at risk for hypertension have been reported to show altered neural responses to psychological tasks, in terms of both involved brain networks and neuropsychological performance [113]. This suggests influences of essential hypertension on the brain may be not always secondary to peripheral BP [113].

\section{Antihypertensive Therapy and Cognition}

The influence of antihypertensive therapy on the risk of dementia was assessed in several longitudinal studies. By June 2010 the results of six main randomised trials considering this issue has been published. On the basis of those trials and five meta-analyses, the American Heart Association/American Stroke Association formed recommendations on the treatment of hypertension in the prevention of dementia. AHA/ASA experts suggest that (1) in patients with stroke lowering of blood pressure is effective in reducing the risk of post-stroke dementia (class I; level of evidence B), (2) there is reasonable evidence that in middle-aged and young elderly subjects, lowering blood pressure can be useful for the prevention of late-life dementia (class IIa; level of evidence B) and (3) the usefulness of lowering blood pressure in people $>80$ years of age for the prevention of dementia is not well established (class IIb; level of evidence B) [114••].

Since that time the results of the ONTARGET/ TRANSCEND study have been published [115•]. The ONTARGET study was a double-blind, double-dummy, randomised controlled trial evaluating the effects of standard doses of an angiotensin-converting enzyme (ACE) inhibitor (ramipril), an angiotensin-receptor blocker (telmisartan) and a combination of the drugs on cardiovascular outcomes in 25 , 620 participants. In the parallel TRANSCEND trial, the effects of telmisartan were compared with those of placebo in 5 , 926 participants intolerant to ACE inhibitors. Secondary endpoints included cognitive impairment and cognitive decline. Over a period of 56 months of follow-up in ONTARGET, cognitive impairment occurred in $652(8 \%)$ of 7,865 patients 
treated with ramipril, $584(7 \%)$ of 7,797 treated with telmisartan and 618 (8\%) of 7,807 treated with combination treatment [combination vs. ramipril, odds ratio (OR) 0.95 , $95 \%$ CI $0.85-1.07, p=0.39$; telmisartan vs. ramipril, OR $0.90,0.80-1.01, p=0.06$ ). In TRANSCEND, cognitive impairment occurred in $239(9 \%)$ of 2,694 participants treated with telmisartan compared with 245 (9\%) of 2,689 allocated placebo (OR 0.97, 0.81-1.17, $p=0.76$ ). There were also no differences in cognitive decline between the groups [115•].

In 2011 Staessen at al. performed a meta-analysis of eight studies. The results showed that blood pressure lowering in all trials combined did not reduce the risk of dementia. However, the reduction was significant $(-18 \%)$ for trials involving a diuretic or dihydropyridine calcium channel blocker as part of active treatment. This was not the case in trials of renin system inhibitors $(+1 \%)$. According to the authors this difference between drug classes might be explained by the amount of blood pressure reduction because in weighted metaregression analysis lowering of systolic pressure explained $41 \%$ $(p=0.08)$ of the risk reduction [116•].

Several smaller studies were published in recent years. Influence of the angiotensin receptor blocker (ARB) eprosartan on trends in cognitive performance was evaluated in the Observational Study on Cognitive Function and SBP Reduction (OSCAR). The main finding of the study published in 2008 was that 6-month hypertensive therapy based on eprosartan was associated with a significant reduction in mean systolic BP (SBP) and a significant improvement in mean Mini-Mental State Examination (MMSE) score $(p<0.0001$ for both outcomes) [117]. The recent analysis was focussed on the influence of eprosartan on trends in cognitive performance in the cohort of patients with difficult-to-treat hypertension (DTTH) (not satisfactorily controlled despite the use of at least 3 antihypertensive drugs). The reduction in BP in the DTTH cohort during the 6-month observation period coincided with a 1-point increase in average MMSE. The mean improvement was similar as in one of the studies indicating therapeutic benefit from cholinesterase inhibitors in patients with Alzheimer's disease [118].

Of interest are the results of a small Japanese study investigating the effect of telmisartan on cognition and regional cerebral blood flow in hypertensive patients with AD. Compared to amlodipine, treatment with telmisartan was not associated with cognitive decline (measured by the ADAS-Jcog test) after 6 months of treatment and, furthermore, improved cerebral blood flow in several brain subregions [119].

A cohort of 599 subjects aged 85 years was enrolled into the Leiden 85-plus Study. Cardiovascular risk factors (among them SBP and DBP) and cognitive performance were assessed annually during a 5-year follow-up. The main finding of the study was that late-life changes in global cognitive function preceded changes in values of vascular risk factors in subsequent years, whereas changes in values of midlife vascular risk factors did not precede changes in global cognitive function [120].

The relationship between blood pressure and WML volume progression was assessed in a study by Verhaaren et al. In a cohort of 665 non-demented subjects, after adjustment for age, sex and cardiovascular risk factors, both systolic and diastolic blood pressures were significantly associated with annual WML progression. After adjustment for baseline WML volume, only SBP remained significantly associated. An interesting finding of the study is that people with uncontrolled untreated hypertension had significantly more WML progression than people with uncontrolled treated hypertension $[78 \bullet$.

After the 6-year follow-up of elderly patients (aged $\geq 65$ and $\leq 80$ years) with a history of treated hypertension (patients with the history of stroke, transient ischaemic attack, diabetes mellitus, atrial fibrillation, cardiac surgery, dementia or depression were excluded), cognitive impairment worsened in the areas related to executive function. Memory did not change [121].

The risk factors for the development of WML were assessed by Vourinen et al. After an average follow-up of 21 years the risk of late-life (65-79 years) WML was associated with midlife hypertension. Both elevation of blood pressure and decrease of blood pressure between midlife and latelife were associated with an increased risk of WML development even after adjustment for antihypertensive therapy [122].

Finally, a small study by Watfa et al. showed that calcium channel blocker (CCB) use might be associated with better memory performance independent of the blood pressure level. The authors suggest that it may be associated with special protective effects of CCB's on cognition [123].

Taken together, the results of the studies evaluating the impact of hypertension treatment on cognitive function are somewhat disappointing. Of note, these studies focussed primarily on white matter changes. Cognitive decline is more closely related to grey matter changes than to white matter changes. Importantly, there is no evidence that treatment of hypertension attenuates the progression of grey matter changes [124•], at least in short-term observations. Continued atrophy in the presence of successful BP reduction stimulates further studies testing the hypothesis that essential hypertension (1) may directly affect the brain via factors that are not mediated by increased BP and (2) from its onset may be a disease of the brain as well as of the vasculature [113]. Studies with longer intervention durations are needed to determine whether successful hypertension treatment would affect the grey matter changes. Recently, the ESH-ESC guidelines have also acknowledged that evidence on antihypertensive therapy and cognition is weak and have preferred not to make any recommendations but to encourage new trials [125]. 


\section{Dementia Prevention Studies}

The aetiology of dementia is multifactorial. It is estimated that up to $50 \%$ of the $\mathrm{AD}$ cases worldwide are attributable to cardiovascular risk factors and physical and cognitive inactivity [126]. Among cardiovascular risk factors reported to promote progressive cognitive decline, reduced cardiac output, atrial fibrillation, left ventricle hypertrophy in midlife as well as coronary heart disease are reported as the leading conditions of the "cardiogenic dementia" [127-130]. Aortic stiffness is thought to be one of the most important extracardiac vascular risk factors playing a crucial role in the initiation of dementia [131]. Interestingly, the presence of the ApoE4 allele, a genetic risk factor for Alzheimer's disease, increases the risk of CAD by $40 \%$ [132].

Vascular risk factors have been shown to be associated with an increased risk of dementia and $\mathrm{AD}$ in several populationbased studies. Interestingly, for diabetes this relation is consistent until late life [133], while for hypertension, hypercholesterolemia and obesity the relationship is not linear and disappears in late life $[23,134,135]$. Similarly, LVH loses its predictive value for cognitive decline in old age [130].

To date the strongest effect towards the prevention of dementia has been observed for antihypertensive treatment, with a hazard ratio of 0.87 (95\% CI 0.76-1.00) [136]. However, the results of longitudinal studies examining the benefit of antihypertensive treatment on cognitive function are not conclusive [137, 138]. Among recent randomised controlled trials examining the impact of antihypertensive therapy on cognitive function, three studies (SYST-EUR, PROGRESS, HOPE) found positive results, while the other four (MRC, SHEP, SCOPE, HYVET-COG) trials reported no significant effects [139]. Consequently, the role of antihypertensive therapy in preventing cognitive disorders remains a matter of debate, especially in elderly free of stroke subjects.

Newly founded in 2011, the European Dementia Prevention Initiative (EDPI) is an important step in further dementia research [140]. Four on-going large RCTs (preDIVA, FINGER, MAPT, ESH-CHL-SHOT) will assess the role of cardiovascular and lifestyle-related risk factor modification in preventing or delaying dementia.

\section{Conclusions}

Hypertension contributes to both early cerebrovascular brain ageing and cognitive decline. Subclinical brain damage including WMLs links hypertension to increased risk of cognitive impairment. Although the relationship between hypertension and dementia is well established, the impact of antihypertensive treatment and management of other risk factors on cognition is less clear. Peripheral BP is probably not an optimal indicator of cerebrovascular health and risk.
It is feasible that more precise assessment of central or regional (brain-specific) BP regulation will increase our knowledge on both cerebrovascular disease and hypertension-related dementia. Further studies based on novel methods of cardiovascular phenotyping and brain imaging are needed. This might improve cerebrovascular risk assessment. One might envisage the introduction of a scoring system evaluating global brain damage risk. Such a NEUROSCORE system, somehow analogous to the cardiovascular EUROSCORE, might result in better prevention of cognitive decline.

Acknowledgments The authors are supported by the Foundation for Polish Science TEAM/2008-2/5 and the National Science Centre MAESTRO UMO-2011/02/A/NZ5/00329 and OPUS UMO-2011/01/B/NZ5/ 01348 grants.

\section{Compliance with Ethics Guidelines}

Conflict of Interest Dariusz Gąsecki, Mariusz Kwarciany, Walenty Nyka and Krzysztof Narkiewicz declare that they have no conflicts of interest.

Human and Animal Rights and Informed Consent This article does not contain any studies with human or animal subjects performed by any of the authors.

Open Access This article is distributed under the terms of the Creative Commons Attribution License which permits any use, distribution, and reproduction in any medium, provided the original author(s) and the source are credited.

\section{References}

Papers of particular interest have been highlighted as:

- Of importance

•• Of major importance

1. MacMahon S, Peto R, Cutler J, Collins R, Sorlie P, Neaton J, et al. Blood pressure, stroke, and coronary heart disease. Part 1, prolonged differences in blood pressure: prospective observational studies corrected for the regression dilution bias. Lancet. 1990;335(8692):765-74.

2. Jellinger KA, Attems J. Prevalence of dementia disorders in the oldest-old: an autopsy study. Acta Neuropathol. 2010;119(4):42133. doi:10.1007/s00401-010-0654-5.

3. - Nelson PT, Head E, Schmitt FA, Davis PR, Neltner JH, Jicha GA, et al. Alzheimer's disease is not "brain aging": neuropathological, genetic, and epidemiological human studies. Acta Neuropathol. 2011;121(5):571-87. doi:10.1007/s00401-011-0826-y. Analysis of specific pathways involved in Alzheimer disease.

4. Barodka VM, Joshi BL, Berkowitz DE, Hogue CW, Nyhan D. Review article: implications of vascular aging. Anesth Analg. 2011;112(5):1048-60. doi:10.1213/ANE.0b013e3182147e3c.

5. Wimo A, Winblad B, Aguero-Torres H, von Strauss E. The magnitude of dementia occurrence in the world. Alzheimer Dis Assoc Disord. 2003;17(2):63-7. 
6. Wimo A, Winblad B, Jonsson L. The worldwide societal costs of dementia: estimates for 2009. Alzheimers Dement. 2010;6(2):98 103. doi:10.1016/j.jalz.2010.01.010.

7. Jicha GA, Parisi JE, Dickson DW, Johnson K, Cha R, Ivnik RJ, et al. Neuropathologic outcome of mild cognitive impairment following progression to clinical dementia. Arch Neurol. 2006;63(5): 674-81. doi:10.1001/archneur.63.5.674.

8. Petersen RC, Doody R, Kurz A, Mohs RC, Morris JC, Rabins PV, et al. Current concepts in mild cognitive impairment. Arch Neurol. 2001;58(12):1985-92.

9. Petersen RC, Smith GE, Waring SC, Ivnik RJ, Tangalos EG, Kokmen E. Mild cognitive impairment: clinical characterization and outcome. Arch Neurol. 1999;56(3):303-8.

10. Hendrie HC. Epidemiology of dementia and Alzheimer's disease. Am J Geriatr Psychiatry. 1998;6(2 Suppl 1):S3-18.

11. Ruitenberg A, Ott A, van Swieten JC, Hofman A, Breteler MM. Incidence of dementia: does gender make a difference? Neurobiol Aging. 2001;22(4):575-80.

12. Roman GC. Vascular dementia revisited: diagnosis, pathogenesis, treatment, and prevention. Med Clin North Am. 2002;86(3):47799.

13. •- Toledo JB, Arnold SE, Raible K, Brettschneider J, Xie SX, Grossman M, et al. Contribution of cerebrovascular disease in autopsy confirmed neurodegenerative disease cases in the National Alzheimer's Coordinating Centre. Brain. 2013. doi:10. 1093/brain/awt188. Article summarizing the contribution of cerebrovascular disease to neurodegenerative diseases confirmed by autopsy.

14. Jellinger KA, Attems J. Neuropathology and general autopsy findings in nondemented aged subjects. Clin Neuropathol. 2012;31(2): 87-98.

15. Chui HC, Zarow C, Mack WJ, Ellis WG, Zheng L, Jagust WJ, et al. Cognitive impact of subcortical vascular and Alzheimer's disease pathology. Ann Neurol. 2006;60(6):677-87. doi:10.1002/ana. 21009.

16. Snowdon DA, Greiner LH, Mortimer JA, Riley KP, Greiner PA, Markesbery WR. Brain infarction and the clinical expression of Alzheimer disease. The Nun Study. JAMA. 1997;277(10):813-7.

17. Shehab A, Abdulle A. Cognitive and autonomic dysfunction measures in normal controls, white coat and borderline hypertension. BMC Cardiovasc Disord. 2011;11:3. doi:10.1186/1471-2261-11-3.

18. Mahoney JR, Verghese J, Goldin Y, Lipton R, Holtzer R. Alerting, orienting, and executive attention in older adults. J Int Neuropsychol Soc. 2010;16(5):877-89. doi:10.1017/s1355617710000767.

19. Richmond R, Law J, Kay-Lambkin F. Higher blood pressure associated with higher cognition and functionality among centenarians in Australia. Am J Hypertens. 2011;24(3):299-303. doi:10.1038/ ajh.2010.236

20. Szewieczek J, Dulawa J, Gminski J, Kurek A, Legierska K, Francuz $\mathrm{T}$, et al. Better cognitive and physical performance is associated with higher blood pressure in centenarians. J Nutr Health Aging. 2011;15(8):618-22.

21. Launer LJ, Masaki K, Petrovitch H, Foley D, Havlik RJ. The association between midlife blood pressure levels and late-life cognitive function. The Honolulu-Asia Aging Study. JAMA. 1995;274(23):1846-51.

22. Elias MF, Wolf PA, D'Agostino RB, Cobb J, White LR. Untreated blood pressure level is inversely related to cognitive functioning: the Framingham Study. Am J Epidemiol. 1993;138(6):353-64.

23. Whitmer RA, Sidney S, Selby J, Johnston SC, Yaffe K. Midlife cardiovascular risk factors and risk of dementia in late life. Neurology. 2005;64(2):277-81. doi:10.1212/01.wnl.0000149519. 47454.f2.

24. Qiu C, Winblad B, Fratiglioni L. The age-dependent relation of blood pressure to cognitive function and dementia. Lancet Neurol. 2005;4(8):487-99. doi:10.1016/s1474-4422(05)70141-1.
25. Launer LJ, Ross GW, Petrovitch H, Masaki K, Foley D, White LR, et al. Midlife blood pressure and dementia: the Honolulu-Asia aging study. Neurobiol Aging. 2000;21(1):49-55.

26. Yamada M, Kasagi F, Sasaki H, Masunari N, Mimori Y, Suzuki G. Association between dementia and midlife risk factors: the Radiation Effects Research Foundation Adult Health Study. J Am Geriatr Soc. 2003;51(3):410-4.

27. Goldstein FC, Levey AI, Steenland NK. High blood pressure and cognitive decline in mild cognitive impairment. J Am Geriatr Soc. 2013;61(1):67-73. doi:10.1111/jgs.12067.

28. Reijmer YD, van den Berg E, Dekker JM, Nijpels G, Stehouwer CD, Kappelle LJ, et al. Development of vascular risk factors over 15 years in relation to cognition: the Hoorn Study. J Am Geriatr Soc. 2012;60(8):1426-33. doi:10.1111/j. 1532-5415.2012.04081.x.

29. • Launer LJ, Hughes T, Yu B, Masaki K, Petrovitch H, Ross GW, et al. Lowering midlife levels of systolic blood pressure as a public health strategy to reduce late-life dementia: perspective from the Honolulu Heart Program/Honolulu Asia Aging Study. Hypertension. 2010;55(6):1352-9. doi:10.1161/hypertensionaha. 109.147389. Important study indicating that reduction of SBP may be effective in prevention of late-life dementia.

30. - Ronnemaa E, Zethelius B, Lannfelt L, Kilander L. Vascular risk factors and dementia: 40-year follow-up of a populationbased cohort. Dement Geriatr Cogn Disord. 2011;31(6):460-6. doi:10.1159/000330020. Seminal study showing in a long-term follow-up (up to 40 years) that vascular risk factors increase the risk of dementia, particularly vascular and mixed dementia, but not $A D$.

31. Laitala VS, Kaprio J, Koskenvuo M, Raiha I, Rinne JO, Silventoinen K. Association and causal relationship of midlife obesity and related metabolic disorders with old age cognition. Curr Alzheimer Res. 2011;8(6):699-706.

32. Banach M, Hering D, Narkiewicz K, Mysliwiec M, Rysz J, Malyszko J. Lipids, blood pressure, kidney-what was new in 2012? Int J Pharmacol. 2012;8(8):659-78.

33. Banach M, Nikfar S, Rahimi R, Bielecka-Dabrowa A, Pencina MJ, Mikhailidis DP, et al. The effects of statins on blood pressure in normotensive or hypertensive subjects - A meta-analysis of randomized controlled trials. Int J Cardiol. 2013. doi:10.1016/j.ijcard. 2013.03.068

34. Banach M, Aronow WS. Hypertension therapy in the older adultsdo we know the answers to all the questions? The status after publication of the ACCF/AHA 2011 expert consensus document on hypertension in the elderly. J Hum Hypertens. 2012;26(11):6413. doi:10.1038/jhh.2012.3.

35. Tzourio C, Dufouil C, Ducimetiere P, Alperovitch A. Cognitive decline in individuals with high blood pressure: a longitudinal study in the elderly. EVA Study Group. Epidemiology of Vascular Aging. Neurology. 1999;53(9):1948-52.

36. Elias MF, Elias PK, Sullivan LM, Wolf PA, D'Agostino RB. Lower cognitive function in the presence of obesity and hypertension: the Framingham heart study. Int J Obes Relat Metab Disord. 2003;27(2):260-8. doi:10.1038/sj.ijo.802225.

37. Hebert LE, Scherr PA, Bennett DA, Bienias JL, Wilson RS, Morris $\mathrm{MC}$, et al. Blood pressure and late-life cognitive function change: a biracial longitudinal population study. Neurology. 2004;62(11): 2021-4.

38. Tervo S, Kivipelto M, Hanninen T, Vanhanen M, Hallikainen M, Mannermaa A, et al. Incidence and risk factors for mild cognitive impairment: a population-based three-year follow-up study of cognitively healthy elderly subjects. Dement Geriatr Cogn Disord. 2004;17(3):196-203. doi:10.1159/000076356.

39. Glynn RJ, Beckett LA, Hebert LE, Morris MC, Scherr PA, Evans DA. Current and remote blood pressure and cognitive decline. JAMA. 1999;281(5):438-45. 
40. Bohannon AD, Fillenbaum GG, Pieper CF, Hanlon JT, Blazer DG. Relationship of race/ethnicity and blood pressure to change in cognitive function. J Am Geriatr Soc. 2002;50(3):424-9.

41. Yasar S, Ko JY, Nothelle S, Mielke MM, Carlson MC. Evaluation of the effect of systolic blood pressure and pulse pressure on cognitive function: the Women's Health and Aging Study II. PLoS One. 2011;6(12):e27976. doi:10.1371/journal.pone.0027976.

42. Kimm H, Lee PH, Shin YJ, Park KS, Jo J, Lee Y, et al. Mid-life and late-life vascular risk factors and dementia in Korean men and women. Arch Gerontol Geriatr. 2011;52(3):e117-22. doi:10.1016/ j.archger.2010.09.004.

43. Ninomiya T, Ohara T, Hirakawa Y, Yoshida D, Doi Y, Hata J, et al. Midlife and late-life blood pressure and dementia in Japanese elderly: the Hisayama study. Hypertension. 2011;58(1):22-8. doi:10. 1161/hypertensionaha.110.163055.

44. Oveisgharan S, Hachinski V. Hypertension, executive dysfunction, and progression to dementia: the canadian study of health and aging. Arch Neurol. 2010;67(2):187-92. doi:10.1001/archneurol.2009. 312.

45. Skoog I, Lernfelt B, Landahl S, Palmertz B, Andreasson LA, Nilsson L, et al. 15-year longitudinal study of blood pressure and dementia. Lancet. 1996;347(9009):1141-5.

46. Molander L, Gustafson Y, Lovheim H. Longitudinal associations between blood pressure and dementia in the very old. Dement Geriatr Cogn Disord. 2010;30(3):269-76. doi:10.1159/000320252.

47. Staessen JA, Richart T, Birkenhager WH. Less atherosclerosis and lower blood pressure for a meaningful life perspective with more brain. Hypertension. 2007;49(3):389-400. doi:10.1161/01.HYP. 0000258151.00728.d8.

48. Kivipelto M, Helkala EL, Laakso MP, Hanninen T, Hallikainen M, Alhainen $\mathrm{K}$, et al. Midlife vascular risk factors and Alzheimer's disease in later life: longitudinal, population based study. BMJ. 2001;322(7300):1447-51.

49. Wu C, Zhou D, Wen C, Zhang L, Como P, Qiao Y. Relationship between blood pressure and Alzheimer's disease in Linxian County, China. Life Sci. 2003;72(10):1125-33.

50. Ueda K, Kawano H, Hasuo Y, Fujishima M. Prevalence and etiology of dementia in a Japanese community. Stroke. 1992;23(6):798803.

51. Kuusisto J, Koivisto K, Mykkanen L, Helkala EL, Vanhanen M, Hanninen $\mathrm{T}$, et al. Association between features of the insulin resistance syndrome and Alzheimer's disease independently of apolipoprotein E4 phenotype: cross sectional population based study. BMJ. 1997;315(7115):1045-9.

52. Brayne C, Gill C, Huppert FA, Barkley C, Gehlhaar E, Girling DM, et al. Vascular risks and incident dementia: results from a cohort study of the very old. Dement Geriatr Cogn Disord. 1998;9(3):175-80.

53. Posner HB, Tang MX, Luchsinger J, Lantigua R, Stern Y, Mayeux R. The relationship of hypertension in the elderly to $\mathrm{AD}$, vascular dementia, and cognitive function. Neurology. 2002;58(8):1175-81.

54. Qiu C, von Strauss E, Fastbom J, Winblad B, Fratiglioni L. Low blood pressure and risk of dementia in the Kungsholmen project: a 6-year follow-up study. Arch Neurol. 2003;60(2):223-8.

55. Yang YH, Roe CM, Morris JC. Relationship between late-life hypertension, blood pressure, and Alzheimer's disease. Am J Alzheimers Dis Other Demen. 2011;26(6):457-62. doi:10.1177/ 1533317511421779 .

56. Farkas E, Luiten PG. Cerebral microvascular pathology in aging and Alzheimer's disease. Prog Neurobiol. 2001;64(6):575-611.

57. Kalaria RN. Linking cerebrovascular defense mechanisms in brain ageing and Alzheimer's disease. Neurobiol Aging. 2009;30(9): 1512-4. doi:10.1016/j.neurobiolaging.2007.10.020.

58. Park L, Anrather J, Girouard H, Zhou P, Iadecola C. Nox2-derived reactive oxygen species mediate neurovascular dysregulation in the aging mouse brain. J Cereb Blood Flow Metab. 2007;27(12):190818. doi:10.1038/sj.jcbfm.9600491.

59. • Hajjar I, Zhao P, Alsop D, Novak V. Hypertension and cerebral vasoreactivity: a continuous arterial spin labeling magnetic resonance imaging study. Hypertension. 2010;56(5):859-64. doi:10. 1161/hypertensionaha.110.160002. This article provides an interesting explanation of the role of hypertension in impairments in mobility, cognition, and mood.

60. Hajjar I, Quach L, Yang F, Chaves PH, Newman AB, Mukamal K, et al. Hypertension, white matter hyperintensities, and concurrent impairments in mobility, cognition, and mood: the Cardiovascular Health Study. Circulation. 2011;123(8):858-65. doi:10.1161/ circulationaha.110.978114.

61. Panerai RB. Assessment of cerebral pressure autoregulation in humans-a review of measurement methods. Physiol Meas. 1998;19(3):305-38.

62. Lojkowska W, Ryglewicz D, Jedrzejczak T, Minc S, Jakubowska T, Jarosz H, et al. The effect of cholinesterase inhibitors on the regional blood flow in patients with Alzheimer's disease and vascular dementia. J Neurol Sci. 2003;216(1):119-26.

63. - Appelman AP, Vincken KL, van der Graaf Y, Vlek AL, Witkamp TD, Mali WP, et al. White matter lesions and lacunar infarcts are independently and differently associated with brain atrophy: the SMART-MR study. Cerebrovasc Dis. 2010;29(1):28-35. doi:10. 1159/000255971. Important study suggesting an independent role for WML in the pathogenesis of brain atrophy.

64. Romanowski CA, Wilkinson ID. Atrophy: when too much atrophy is too little brain. Neuroradiology. 2011;53 Suppl 1:S133-9. doi:10. 1007/s00234-011-0929-0.

65. Raz N, Rodrigue KM, Haacke EM. Brain aging and its modifiers: insights from in vivo neuromorphometry and susceptibility weighted imaging. Ann N Y Acad Sci. 2007;1097:84-93. doi:10.1196/ annals. 1379.018.

66. Raz N, Rodrigue KM, Kennedy KM, Acker JD. Vascular health and longitudinal changes in brain and cognition in middle-aged and older adults. Neuropsychology. 2007;21(2):149-57. doi:10.1037/ 0894-4105.21.2.149.

67. Raz N, Lindenberger U, Rodrigue KM, Kennedy KM, Head D, Williamson A, et al. Regional brain changes in aging healthy adults: general trends, individual differences and modifiers. Cereb Cortex. 2005;15(11):1676-89. doi:10.1093/cercor/bhi044.

68. Chen X, Wen W, Anstey KJ, Sachdev PS. Effects of cerebrovascular risk factors on gray matter volume in adults aged 60-64 years: a voxel-based morphometric study. Psychiatry Res. 2006;147(2-3): 105-14. doi:10.1016/j.pscychresns.2006.01.009.

69. Taki Y, Goto R, Evans A, Zijdenbos A, Neelin P, Lerch J, et al. Voxel-based morphometry of human brain with age and cerebrovascular risk factors. Neurobiol Aging. 2004;25(4):455-63. doi:10. 1016/j.neurobiolaging.2003.09.002.

70. Strassburger TL, Lee HC, Daly EM, Szczepanik J, Krasuski JS, Mentis MJ, et al. Interactive effects of age and hypertension on volumes of brain structures. Stroke. 1997;28(7):1410-7.

71. Gunning-Dixon FM, Brickman AM, Cheng JC, Alexopoulos GS. Aging of cerebral white matter: a review of MRI findings. Int $\mathrm{J}$ Geriatr Psychiatry. 2009;24(2):109-17. doi:10.1002/gps.2087.

72. Hachinski VC, Potter P, Merskey H. Leuko-araiosis. Arch Neurol. 1987;44(1):21-3.

73. - Debette S, Markus HS. The clinical importance of white matter hyperintensities on brain magnetic resonance imaging: systematic review and meta-analysis. BMJ. 2010;341:c3666. doi:10.1136/bmj. c3666. A systematic analysis of clinical relevance of WMH.

74. Xiong YY, Mok V. Age-related white matter changes. J Aging Res. 2011;2011:617927. doi:10.4061/2011/617927.

75. • Pantoni L. Cerebral small vessel disease: from pathogenesis and clinical characteristics to therapeutic challenges. Lancet Neurol. 2010;9(7):689-701. doi:10.1016/S1474-4422(10)70104-6. 
Elegant review summarizing the evidence linking cerebral WMH to pathogenesis and clinical characteristics of cognitive decline.

76. Skoog I. A review on blood pressure and ischaemic white matter lesions. Dement Geriatr Cogn Disord. 1998;9 Suppl 1:13-9.

77. Longstreth Jr WT, Manolio TA, Arnold A, Burke GL, Bryan $\mathrm{N}$, Jungreis CA, et al. Clinical correlates of white matter findings on cranial magnetic resonance imaging of 3301 elderly people. The Cardiovascular Health Study. Stroke. 1996;27(8):1274-82.

78. • Verhaaren BF, Vernooij MW, de Boer R, Hofman A, Niessen WJ, van der Lugt A, et al. High blood pressure and cerebral white matter lesion progression in the general population. Hypertension. 2013;61(6):1354-9. doi:10.1161/hypertensionaha.111.00430. This study demonstrates that hypertension treatment could reduce WML progression in the general population .

79. Knopman DS, Penman AD, Catellier DJ, Coker LH, Shibata DK, Sharrett AR, et al. Vascular risk factors and longitudinal changes on brain MRI: the ARIC study. Neurology. 2011;76(22):1879-85. doi: 10.1212/WNL.0b013e31821d753f.

80. Marcus J, Gardener H, Rundek T, Elkind MS, Sacco RL, Decarli C, et al. Baseline and longitudinal increases in diastolic blood pressure are associated with greater white matter hyperintensity volume: the northern Manhattan study. Stroke. 2011;42(9):2639-41. doi:10. 1161/strokeaha.111.617571.

81. Raz N, Yang YQ, Rodrigue KM, Kennedy KM, Lindenberger U, Ghisletta P. White matter deterioration in 15 months: latent growth curve models in healthy adults. Neurobiol Aging. 2012;33(2): 429.e1-5. doi:10.1016/j.neurobiolaging.2010.11.018.

82. Salat DH, Williams VJ, Leritz EC, Schnyer DM, Rudolph JL, Lipsitz LA, et al. Inter-individual variation in blood pressure is associated with regional white matter integrity in generally healthy older adults. Neuroimage. 2012;59(1):181-92. doi:10.1016/j. neuroimage.2011.07.033.

83. Raz N, Yang Y, Dahle CL, Land S. Volume of white matter hyperintensities in healthy adults: contribution of age, vascular risk factors, and inflammation-related genetic variants. Biochim Biophys Acta. 2012;1822(3):361-9. doi:10.1016/j.bbadis.2011.08. 007.

84. Murray AD, Staff RT, McNeil CJ, Salarirad S, Starr JM, Deary IJ, et al. Brain lesions, hypertension and cognitive ageing in the 1921 and 1936 Aberdeen birth cohorts. Age (Dordr). 2012;34(2):451-9. doi:10.1007/s11357-011-9233-5.

85. Maillard P, Carmichael O, Fletcher E, Reed B, Mungas D, DeCarli C. Coevolution of white matter hyperintensities and cognition in the elderly. Neurology. 2012;79(5):442-8. doi:10.1212/WNL. 0b013e3182617136.

86. Haan M, Espeland MA, Klein BE, Casanova R, Gaussoin SA, Jackson RD, et al. Cognitive function and retinal and ischemic brain changes: the Women's Health Initiative. Neurology. 2012;78(13): 942-9. doi:10.1212/WNL.0b013e31824d9655.

87. Loitfelder M, Seiler S, Schwingenschuh P, Schmidt R. Cerebral microbleeds: a review. Panminerva Med. 2012;54(3):149-60.

88. Waldstein SR, Rice SC, Thayer JF, Najjar SS, Scuteri A, Zonderman AB. Pulse pressure and pulse wave velocity are related to cognitive decline in the Baltimore Longitudinal Study of Aging. Hypertension. 2008;51(1):99-104. doi:10.1161/hypertensionaha. 107.093674.

89. Qiu C, Winblad B, Viitanen M, Fratiglioni L. Pulse pressure and risk of Alzheimer disease in persons aged 75 years and older: a community-based, longitudinal study. Stroke. 2003;34(3):594-9. doi:10.1161/01.str.0000060127.96986.f4.

90. Lee AY, Jeong SH, Choi BH, Sohn EH, Chui H. Pulse pressure correlates with leukoaraiosis in Alzheimer disease. Arch Gerontol Geriatr. 2006;42(2):157-66. doi:10.1016/j.archger.2005.06.009.

91. Weller RO, Boche D, Nicoll JA. Microvasculature changes and cerebral amyloid angiopathy in Alzheimer's disease and their potential impact on therapy. Acta Neuropathol. 2009;118(1):87102. doi:10.1007/s00401-009-0498-z.

92. Kearney-Schwartz A, Rossignol P, Bracard S, Felblinger J, Fay R, Boivin JM, et al. Vascular structure and function is correlated to cognitive performance and white matter hyperintensities in older hypertensive patients with subjective memory complaints. Stroke. 2009;40(4):1229-36. doi:10.1161/strokeaha.108.532853.

93. Nation DA, Wierenga CE, Delano-Wood L, Jak AJ, Delis DC, Salmon DP, et al. Elevated pulse pressure is associated with agerelated decline in language ability. J Int Neuropsychol Soc. 2010;16(5):933-8. doi:10.1017/s1355617710000548.

94. Pase MP, Pipingas A, Kras M, Nolidin K, Gibbs AL, Wesnes KA, et al. Healthy middle-aged individuals are vulnerable to cognitive deficits as a result of increased arterial stiffness. J Hypertens. 2010;28(8):1724-9. doi:10.1097/HJH.0b013e32833b1ee7.

95. Nation DA, Delano-Wood L, Bangen KJ, Wierenga CE, Jak AJ, Hansen LA, et al. Antemortem pulse pressure elevation predicts cerebrovascular disease in autopsy-confirmed Alzheimer's disease. J Alzheimers Dis. 2012;30(3):595-603. doi:10.3233/jad-2012111697.

96. • Rabkin SW, Jarvie G. Comparison of vascular stiffness in vascular dementia, Alzheimer dementia and cognitive impairment. Blood Press. 2011;20(5):274-83. doi:10.3109/08037051.2011.566246. This paper systematically analyzes the associations between vascular stiffness and cognitive function and shows that vascular stiffness is greater in VaD compared with $A D$.

97. Zhong W, Cruickshanks KJ, Schubert CR, Carlsson CM, Chappell RJ, Klein BE, et al. Pulse Wave Velocity and Cognitive Function in Older Adults. Alzheimer Dis Assoc Disord. 2013. doi:10.1097/ WAD.0b013e3182949f06.

98. Diz DI, Lewis K. Dahl memorial lecture: the renin-angiotensin system and aging. Hypertension. 2008;52(1):37-43. doi:10.1161/ HYPERTENSIONAHA.107.108985.

99. Gustafson DR, Melchior L, Eriksson E, Sundh V, Blennow K, Skoog I. The ACE insertion deletion polymorphism relates to dementia by metabolic phenotype, APOEepsilon4, and age of dementia onset. Neurobiol Aging. 2010;31(6):910-6. doi:10.1016/j. neurobiolaging.2008.07.015.

100. Bourassa EA, Sved AF, Speth RC. Angiotensin modulation of rostral ventrolateral medulla (RVLM) in cardiovascular regulation. Mol Cell Endocrinol. 2009;302(2):167-75. doi:10.1016/j.mce. 2008.10.039.

101. Basso N, Paglia N, Stella I, de Cavanagh EM, Ferder L, del Rosario Lores Arnaiz M, et al. Protective effect of the inhibition of the reninangiotensin system on aging. Regul Pept. 2005;128(3):247-52. doi: 10.1016/j.regpep.2004.12.027.

102. Berti V, Osorio RS, Mosconi L, Li Y, De Santi S, de Leon MJ. Early detection of Alzheimer's disease with PET imaging. Neurodegener Dis. 2010;7(1-3):131-5. doi:10.1159/000289222.

103. Attwell D, Iadecola $\mathrm{C}$. The neural basis of functional brain imaging signals. Trends Neurosci. 2002;25(12):621-5.

104. de Leon MJ, Convit A, Wolf OT, Tarshish CY, DeSanti S, Rusinek $\mathrm{H}$, et al. Prediction of cognitive decline in normal elderly subjects with 2-[(18)F]fluoro-2-deoxy-D-glucose/poitron-emission tomography (FDG/PET). Proc Natl Acad Sci U S A. 2001;98(19): 10966-71. doi:10.1073/pnas.191044198.

105. Mosconi L, Berti V, Glodzik L, Pupi A, De Santi S, de Leon MJ. Pre-clinical detection of Alzheimer's disease using FDG-PET, with or without amyloid imaging. J Alzheimers Dis. 2010;20(3):843-54. doi:10.3233/JAD-2010-091504.

106. Raber J, Huang Y, Ashford JW. ApoE genotype accounts for the vast majority of $\mathrm{AD}$ risk and $\mathrm{AD}$ pathology. Neurobiol Aging. 2004;25(5):641-50. doi:10.1016/j.neurobiolaging.2003.12.023.

107. Chuang YF, Hayden KM, Norton MC, Tschanz J, Breitner JC, Welsh-Bohmer KA, et al. Association between APOE epsilon 4 allele and vascular dementia: the Cache County 
study. Dement Geriatr Cogn Disord. 2010;29(3):248-53. doi: $10.1159 / 000285166$.

108. Yasuno F, Tanimukai S, Sasaki M, Ikejima C, Yamashita F, Kodama $\mathrm{C}$, et al. Effect of plasma lipids, hypertension and APOE genotype on cognitive decline. Neurobiol Aging. 2012;33(11):2633-40. doi: 10.1016/j.neurobiolaging.2011.12.028.

109. Schuur M, van Swieten JC, Schol-Gelok S, Ikram MA, Vernooij MW, Liu F, et al. Genetic risk factors for cerebral small-vessel disease in hypertensive patients from a genetically isolated population. J Neurol Neurosurg Psychiatry. 2011;82(1):41-4. doi:10.1136/ jnnp.2009.176362.

110. Markovitz JH, Jonas BS, Davidson K. Psychologic factors as precursors to hypertension. Curr Hypertens Rep. 2001;3(1):25-32.

111. Sparrenberger F, Cichelero FT, Ascoli AM, Fonseca FP, Weiss G, Berwanger O, et al. Does psychosocial stress cause hypertension? A systematic review of observational studies. J Hum Hypertens. 2009;23(1):12-9. doi:10.1038/jhh.2008.74.

112. - Jennings JR, Heim AF. From brain to behavior: hypertension's modulation of cognition and affect. Int J Hypertens. 2012;2012: 701385. doi:10.1155/2012/701385. This review provides evidence for an impact of blood pressure on the psychological factors.

113. Jennings JR, Zanstra Y. Is the brain the essential in hypertension? Neuroimage. 2009;47(3):914-21. doi:10.1016/j.neuroimage.2009. 04.072 .

114. • Gorelick PB, Scuteri A, Black SE, Decarli C, Greenberg SM, Iadecola $\mathrm{C}$, et al. Vascular contributions to cognitive impairment and dementia: a statement for healthcare professionals from the american heart association/american stroke association. Stroke. 2011;42(9): 2672-713. doi:10.1161/STR.0b013e3182299496. Statement summarizing the current knowledge regarding the contribution of vascular risk factors to cognitive impairment and dementia.

115. - Anderson C, Teo K, Gao P, Arima H, Dans A, Unger T, et al. Renin-angiotensin system blockade and cognitive function in patients at high risk of cardiovascular disease: analysis of data from the ONTARGET and TRANSCEND studies. Lancet Neurol. 2011;10(1):43-53. doi:10.1016/s1474-4422(10)70250-7. This article summarizes the effects of different approaches of RAA system inhibition on cognitive outcomes in ONTARGET/ TRANSCEND trial.

116. - Staessen JA, Thijs L, Richart T, Odili AN, Birkenhager WH. Placebo-controlled trials of blood pressure-lowering therapies for primary prevention of dementia. Hypertension. vol 2. United States2011. p. e6-7. An update of the meta-analysis of the placebo controlled trials regarding the blood-pressure lowering therapies for the primary prevention of dementia.

117. Hanon O, Berrou JP, Negre-Pages L, Goch JH, Nadhazi Z, Petrella $\mathrm{R}$, et al. Effects of hypertension therapy based on eprosartan on systolic arterial blood pressure and cognitive function: primary results of the Observational Study on Cognitive function And Systolic Blood Pressure Reduction open-label study. J Hypertens. 2008;26(8):1642-50. doi:10.1097/HJH. 0b013e328301a280.

118. Petrella RJ, Shlyakhto E, Konradi AO, Berrou JP, Sedefdjian A, Pathak A. Blood pressure responses to hypertension treatment and trends in cognitive function in patients with initially difficult-to-treat hypertension: a retrospective subgroup analysis of the Observational Study on Cognitive Function and SBP Reduction (OSCAR) study. J Clin Hypertens (Greenwich). 2012;14(2):78-84. doi:10.1111/j. 1751-7176.2011.00577.x.

119. Kume K, Hanyu H, Sakurai H, Takada Y, Onuma T, Iwamoto T. Effects of telmisartan on cognition and regional cerebral blood flow in hypertensive patients with Alzheimer's disease. Geriatr Gerontol Int. 2012;12(2):207-14. doi:10.1111/j.14470594.2011.00746.x.

120. van Vliet $\mathrm{P}$, Westendorp RG, van Heemst D, de Craen AJ, Oleksik AM. Cognitive decline precedes late-life longitudinal changes in vascular risk factors. J Neurol Neurosurg Psychiatry. 2010;81(9): 1028-32. doi:10.1136/jnnp.2009.182519.

121. Vicario A, del Sueldo MA, Zilberman JM, Cerezo GH. Cognitive evolution in hypertensive patients: a six-year follow-up. Vasc Health Risk Manag. 2011;7:281-5. doi:10.2147/vhrm.s18777.

122. Vuorinen M, Solomon A, Rovio S, Nieminen L, Kareholt I, Tuomilehto J, et al. Changes in vascular risk factors from midlife to late life and white matter lesions: a 20-year follow-up study. Dement Geriatr Cogn Disord. 2011;31(2):119-25. doi:10.1159/ 000323810 .

123. Watfa G, Rossignol P, Kearney-Schwartz A, Fay R, Bracard S, Felblinger $\mathrm{J}$, et al. Use of calcium channel blockers is associated with better cognitive performance in older hypertensive patients with subjective memory complaints. J Hypertens. 2010;28(12): 2485-93. doi:10.1097/HJH.0b013e32833e4108.

124. • Jennings JR, Mendelson DN, Muldoon MF, Ryan CM, Gianaros PJ, Raz N, et al. Regional grey matter shrinks in hypertensive individuals despite successful lowering of blood pressure. J Hum Hypertens. 2012;26(5):295-305. doi:10.1038/jhh.2011.31. This is a novel study demonstrating that essential hypertension is associated with grey matter shrinkage, and that reduction of BP may not counter that trend.

125. Mancia G, Fagard R, Narkiewicz K, Redon J, Zanchetti A, Bohm M, et al. 2013 ESH/ESC Guidelines for the management of arterial hypertension: the Task Force for the management of arterial hypertension of the European Society of Hypertension (ESH) and of the European Society of Cardiology (ESC). J Hypertens. 2013;31(7):1281-357. doi: 10.1097/01.hjh.0000431740.32696.cc.

126. Barnes DE, Yaffe K. The projected effect of risk factor reduction on Alzheimer's disease prevalence. Lancet Neurol. 2011;10(9):81928. doi:10.1016/s1474-4422(11)70072-2.

127. Jefferson AL, Tate DF, Poppas A, Brickman AM, Paul RH, Gunstad $\mathrm{J}$, et al. Lower cardiac output is associated with greater white matter hyperintensities in older adults with cardiovascular disease. J Am Geriatr Soc. 2007;55(7):1044-8. doi:10.1111/j.1532-5415.2007. 01226.x.

128. Singh-Manoux A, Sabia S, Kivimaki M, Shipley MJ, Ferrie JE, Marmot MG. Cognition and incident coronary heart disease in late midlife: the Whitehall II study. Intelligence. 2009;37(6):529-34. doi:10.1016/j.intell.2008.12.001.

129. Ott A, Breteler MM, de Bruyne MC, van Harskamp F, Grobbee DE, Hofman A. Atrial fibrillation and dementia in a population-based study. The Rotterdam Study. Stroke. 1997;28(2):316-21.

130. Kähönen-Väre $M$, Brunni-Hakala S, Lindroos M, Pitkala K, Strandberg T, Tilvis R. Left ventricular hypertrophy and blood pressure as predictors of cognitive decline in old age. Aging Clin Exp Res. 2004;16(2):147-52.

131. Mitchell GF, van Buchem MA, Sigurdsson S, Gotal JD, Jonsdottir MK, Kjartansson Ó, et al. Arterial stiffness, pressure and flow pulsatility and brain structure and function: the Age, Gene/ Environment Susceptibility-Reykjavik study. Brain. 2011;134(Pt 11):3398-407. doi:10.1093/brain/awr253.

132. Kotze MJ, van Rensburg SJ. Pathology supported genetic testing and treatment of cardiovascular disease in middle age for prevention of Alzheimer's disease. Metab Brain Dis. 2012;27(3):255-66. doi: 10.1007/s11011-012-9296-8.

133. Biessels GJ, Staekenborg S, Brunner E, Brayne C, Scheltens P. Risk of dementia in diabetes mellitus: a systematic review. Lancet Neurol. 2006;5(1):64-74. doi:10.1016/s1474-4422(05) 70284-2.

134. Fitzpatrick AL, Kuller LH, Lopez OL, Diehr P, O’Meara ES, Longstreth WT, et al. Midlife and late-life obesity and the risk of dementia: cardiovascular health study. Arch Neurol. 2009;66(3): 336-42. doi:10.1001/archneurol.2008.582. 
135. Mielke MM, Zandi PP, Shao H, Waern M, Östling S, Guo X, et al. The 32-year relationship between cholesterol and dementia from midlife to late life. Neurology. 2010;75(21):1888-95. doi:10.1212/ WNL.0b013e3181feb2bf.

136. Peters R, Beckett N, Forette F, Tuomilehto J, Clarke R, Ritchie C, et al. Incident dementia and blood pressure lowering in the Hypertension in the Very Elderly Trial cognitive function assessment (HYVET-COG): a double-blind, placebo controlled trial. Lancet Neurol. 2008;7(8):683-9. doi:10.1016/S1474-4422(08)70143-1.

137. Grassi D, Ferri L, Cheli P, Di Giosia P, Ferri C. Cognitive decline as a consequence of essential hypertension. Curr Pharm Des. 2011;17(28):3032-8.
138. Guan JW, Huang CQ, Li YH, Wan CM, You C, Wang ZR, et al. No association between hypertension and risk for Alzheimer's disease: a meta-analysis of longitudinal studies. J Alzheimers Dis. 2011;27(4):799-807. doi:10.3233/jad-2011111160.

139. Duron E, Hanon O. Antihypertensive treatments, cognitive decline, and dementia. J Alzheimers Dis. 2010;20(3):903-14. doi:10.3233/ jad-2010-091552.

140. Richard E, Andrieu S, Solomon A, Mangialasche F, Ahtiluoto S, Moll van Charante EP, et al. Methodological challenges in designing dementia prevention trials - the European Dementia Prevention Initiative (EDPI). J Neurol Sci. 2012;322(1-2):64-70. 